\title{
A ordem Carmelita
}

\author{
Adalgisa Arantes Campos (UFMG, Belo Horizonte, MG) \\ adarantes@terra.com.br
}

Resumo: 0 presente estudo enfoca a origem lendária da Ordem Mendicante Carmelita, que remonta ao Antigo Testamento; sua fundação histórica no século XIII, que está profundamente relacionada às experiências maravilhosas (meraviglia), bem como ao seu percurso e expansão devocional, percebida a partir da ampliação no número de espaços conventuais e de associações de leigos pertencentes à mesma. Daremos especial atenção ao culto carmelita nas Minas Gerais, onde conventos não puderam ser estabelecidos, mas que conta com a presença de monumentos arquitetônicos de grande relevância histórica, religiosa e artística.

Palavras-chave: Ordem Carmelita; Iconografia Carmelita; Cultura do Barroco.

\section{The Carmelite order}

Abstract: This study emphasizes the legendary origin of the Carmelite Order, which dates back the Old Testament. Its historic foundation, in the 18th century, is deeply related to the marvellous experiences (meraviglia), as well as to Carmelite Order's devotional journey and expansion, both noticed through the enlargement of the number of monasteries and layman associations belonging to them. Special attention will be given to the Carmelite cult in Minas Gerais, a region where monasteries couldn't be established, but where we can find architectonic monuments of a great historic, religious and artistic importance.

Keywords: The Carmelite Order; Carmelite Iconography; Baroque Culture.

\section{1 - Introdução ${ }^{1}$}

0 ciclo legendário da Ordem dos Carmelitas - que constitui o repertório iconográfico da mesma - é revelador da relevância que a meraviglia representou na história do Carmelo. Meraviglia ou maravilhoso no português como nos esclarece LE GOFF (2006, p.5-119) pode ser, a priori, definida como um conjunto de fenômenos, seres, objetos, espaços considerados pelo medievo de caráter extraordinário. A meraviglia alimentou-se de diversas fontes, das legendas pagãs da antiguidade até os relatos bíblicos passando pelas estórias míticas do Oriente e pelo paganismo bárbaro. Entretanto, o cristianismo procurou depurar o maravilhoso no Ocidente afirmando ser Deus a única fonte, portanto, ele seria em último caso de origem divina. Dessa maneira, os episódios lendários e/ou míti$\cos$ da ordem carmelita elegidos para compor o brasão constituem momentos de revelação do maravilhoso aos monges e aos seus santos.

\section{2 - Origem Carmelita}

A explicação sobre a origem e a trajetória histórica da Ordem dos Carmelitas se enquadra bem na ótica da meraviglia, pois nelas houve a confluência de aspectos lendário e miraculoso.

Um primeiro momento diz respeito à origem mítica de sua fundação e à pessoa extraordinária de Elias, profeta do Antigo Testamento que viveu na época em que Acab era rei de Israel (880 a.C.). Bem mais tarde, já no século XIII, motivado pela recepção miraculosa do escapulário da própria Nossa Senhora do Carmo, Simão Stock fundou inúmeros conventos no Ocidente. Finalmente, ainda no âmbito do século XIII - período de renovação da vida urbana -, outro momento hierofânico relaciona a devoção ao escapulário ao "privilégio sabatino", conexão feita pelo papa João XXII que teve um sonho revelador que suscitou a Bula Sabatina. Em fins do século XVI, Teresa d' Ávila e São João da Cruz, reformaram o Carmelo. 
Assim sendo, é nosso intuito cuidar dos três momentos "fundadores" da ordem carmelita e simultaneamente dos episódios míticos e fabulosos que influenciaram na concepção iconográfica do brasão identificador, dos atributos dos santos e santas da ordem que foram canonizados pelo menos até o século XVIII e finalmente a difusão dos estabelecimentos conventuais e de terceiros carmelitas no território americano português, atingindo a Capitania das Minas, onde os frades não puderam edificar seus conventos, contudo os terceiros deixaram monumentos arquitetônicos de grande relevância histórica, artística e até mesmo devocional.

\section{3 - A Figura extraordinária de Elias e seu sucessor Eliseu}

Narrativas do Antigo Testamento a respeito do Monte Carmelo - montanha que domina a planície de EsdreIon no deserto do Sinai ${ }^{2}$ - mesclam fatos históricos e prodígios sobre a origem dessa instituição religiosa. Nessa montanha primordial houve certamente importante santuário pagão que atraía numerosos sacerdotes de Baal (1 R 18, 19), divindade relacionada à fertilidade. Elias desafiou esses ideólogos de Acab (1R, 18, 25-44) passando ao fio da espada a quantia fabulosa de 450 sacerdotes, fato que suscitou resposta imediata da rainha Jezabel - fenícia e por isso idólatra - que em seguida ordenou a morte de Elias ( $1 R, 19,1$ - 3). Ocasionalmente o profeta Eliseu, discípulo de Elias, também teria frequentado o Monte Carmelo que acabou se transformando, nos séculos III e IV da era cristã, em concorrido centro de romaria e de retiros espirituais. Em face disso, o Carmelo passou a simbolizar o triunfo da espiritualidade cristã, um espaço consagrado a experiências maravilhosas.

A vida do profeta Elias foi crivada de aspectos extraordinários. Embora obediente ao Senhor, Elias, as narrativas bíblicas descrevem sua personalidade forte que o leva inclusive a repreender e desafiar Javé. Como porta-voz de Deus o profeta age sobre o tempo produzindo uma seca que castigou duramente os povos $(I R, 17,1)$. Jurado de morte por Jezabel, ele busca guarida na casa de uma viúva pobre e temente a Deus e, nesse periodo, também realiza prodígios: as vasilhas de farinha e de azeite não se esgotam até que a chuva volte à normalidade, o filho da dita senhora foi ressuscitado, após doloroso e desafiante clamor: "Javé, meu Deus, queres castigar até essa viúva que me hospeda, fazendo o filho dela morrer?" ( Cf. 1 R 17, 21).

\footnotetext{
Ele vive em colóquios com Deus e tal aderência ao sagrado não o impede de ser crítico e irreverente. Diante da perseguição política busca refúgio no deserto, onde quase se entrega ao desânimo: "Chega Javé! Tira a minha vida, porque eu não sou melhor que meus pais" (1 R 19,5). Reage novamente, alimentando-se do pão e da água miraculosas, adquirindo as forças físicas e espirituais para chegar ao Horeb, o monte de Deus no Sinai. Como prêmio e consolação por sua fé genuína foi conduzido por Javé até Eliseu, doravante discipulo, um substituto político, que recebeu o seu manto, ou seja, o seu benefício, e em contrapartida a sua responsabilidade $(1 \mathrm{R} 19,5)$. Nesse momento o grande profeta é tragado
}

por uma torrente de ventos, desaparecendo em uma carruagem de fogo. Assim sendo, Elias ascende aos céus já que investiu com seu manto o seu sucessor, conferindo-Ihe com tal gesto sua proteção, autoridade espiritual e confirmação de missão.

Desse primeiro momento é importante destacar determinadas imagens: a montanha do Carmelo e o Monte Horeb como culminação da elevação espiritual; a cidade (com suas elites políticas) como adversária a confrontar o profeta; o deserto se contrapondo a urbe significando refúgio seguro e como lugar adequado para a penitência e reconciliação com Deus; a espada com a qual Elias degolou os sacerdotes da idolatria; o manto como proteção e missão religiosa; a carruagem de fogo evadindo de uma paisagem vergel a indicar que Elias não morreu, mas foi transladado em vida para o céu; a nuvenzinha precursora da chuva e como elemento para indicar as aparições sagradas. A representação dos dois profetas (Elias e Eliseu) dá testemunho de fé em um deus único; a figura do anjo traz o pão para alimento, o ânimo e o consolo. Assim sendo, não nos perguntamos se tais milagres foram de fato verdadeiros, mas como tais crenças e narrativas atuaram na iconografia da ordem do Carmelo. Veremos que essas imagens serão importantes para a constituição do brasão e servirão de referências para a criação dos atributos das devoções dos carmelitas ${ }^{3}$.

\section{4 - 0 frade inglês Simão Stock e a recepção miraculosa do escapulário carmelita}

Consta que a regra da Ordem Conventual dos Carmelitas Observantes foi aprovada pelo papa Honório III em 1226 - data em que os cruzados voltavam da Palestina. Como vimos anteriormente a espiritualidade do Carmelo tem seus fundamentos no Oriente. Aliás, considera-se que tenha sido o lugar da fundação da dita ordem.

No século XIII o membro carmelita mais ilustre foi o inglês Simão Stock (1165 - 1265) (LEONARDINI \&t BORDA, 1996, p.235), que viveu seis anos na Terra Santa. Nela, em 15 de julho de 1251, foi agraciado com uma visão na qual recebeu o escapulário de Nossa Senhora juntamente com a recomendação de que o uso desse objeto livraria a alma dos devotos das penas do Inferno e até mesmo daquelas do Purgatório. A palavra escapulário, do latim escapulae (ombros), designava o avental que os religiosos usavam na faina diária para protegerem o hábito. Tal avental transforma-se em uma miniatura de dois pedaços de pano unidos por um barbante, de modo que um fica no peito e outro nas costas para dar proteção maternal ao devoto ${ }^{4}$.

0 frade inglês foi nomeado Superior Geral, tendo fundado conventos em Cambridge, Oxford, Paris e Bolonha, bem como a ordem terceira dos carmelitas. Presume-se então que no Ocidente Simão Stock tenha sido o instituidor da Ordem do Carmelo em um século marcado pela aceleração histórica: retomada do comércio, da vida urbana, com a emergência dos leigos e das mulheres. É nesse contexto de secularização cultural que surgiram precocemente - antes mesmo das ordens segundas (de freiras)-, as ordens terciárias, agremiações de leigos instaladas no 
interior dos complexos arquitetônicos conventuais ou mesmo dentro das igrejas matrizes ${ }^{5}$. É importante destacar que não obstante as mudanças no sentido de racionalizar o pensamento e a cultura, o imaginário social ainda encontrava-se eivado de aspectos do maravilhoso, muito alimentado pelas viagens ao Oriente, notadamente pelas cruzadas. 0 Carmelo, mais do que as outras ordens nascidas no mesmo período e também dotadas de escapulário próprio, a ordem franciscana e a dominicana, ateve-se sobremaneira na meraviglia. A festa em honra do frade inglês é comemorada em 16 de maio.

\section{5 - A bula Sacratíssimo uti culmine, o Privi- légio sabatino e Nossa Senhora do Carmo}

A Igreja Católica deu claras demonstrações de apoio aos religiosos do Carmelo egressos da Terra Santa através do Privilégio Sabatino que suscitou uma incrivel popularidade ao culto da Virgem do Carmo e do seu bentinho. Consta que, no ano de 1322, o papa João XXII, através da bula Sacratíssimo uti culmine, revelou que Nossa Senhora do Carmo "Ihe aparecera e lhe prometera tirar do Purgatório as almas de todos os fiéis que em vida tivessem pertencido à Ordem de Nossa Senhora do Carmo ou à Confraria do Santo Escapulário do Carmo no sábado seguinte à sua morte" (GONÇALVES, 1963, p.11-12). Com o uso do escapulário, símbolo de devoção e consagração à Virgem, o devoto também passou a gozar de indulgências plenas ou parciais.
Posteriormente, a mencionada aparição foi assimilada pela iconografia que passou a destacar a figura do papa e a recepção da bula sabatina. A título de exemplo citamos o medalhão do forro da nave com tal iconografia na Ordem Terceira do Carmo de São João del Rei e na azulejaria das ilhargas da capela-mor dos terceiros carmelitas em Ouro Preto.

Do século XIII, período histórico com uma cultura mais racionalizada, desprovida daqueles aspectos míticos dominantes na época de Elias e Eliseu, conservemos a imagem do hábito usado pelos carmelitas e do escapulário concedido por Nossa Senhora, ambos da mesma cor, ou seja, marrom. Difundiu-se a representação da Virgem com os acessórios da ordem, tem-se então a devoção à Nossa Senhora do Carmo, cuja festa é comemorada em 16 de julho.

Deve-se registrar também que houve a incorporação das representações das almas padecentes e do Purgatório, topografia intermediária do além já chancelada como doutrina através do Concílio de Lião. Nesse "cárcere divino", conforme o aprofundado estudo de Jacques LE GOFF (1995) as almas destinadas à salvação são representadas dentro de um fogo ambivalente que pune, purifica e santifica. Tal fogo redentor é transitório, não é destrutivo e eterno como o fogo do Inferno e por isso mesmo também não deixa de ser em si um verdadeiro prodígio.

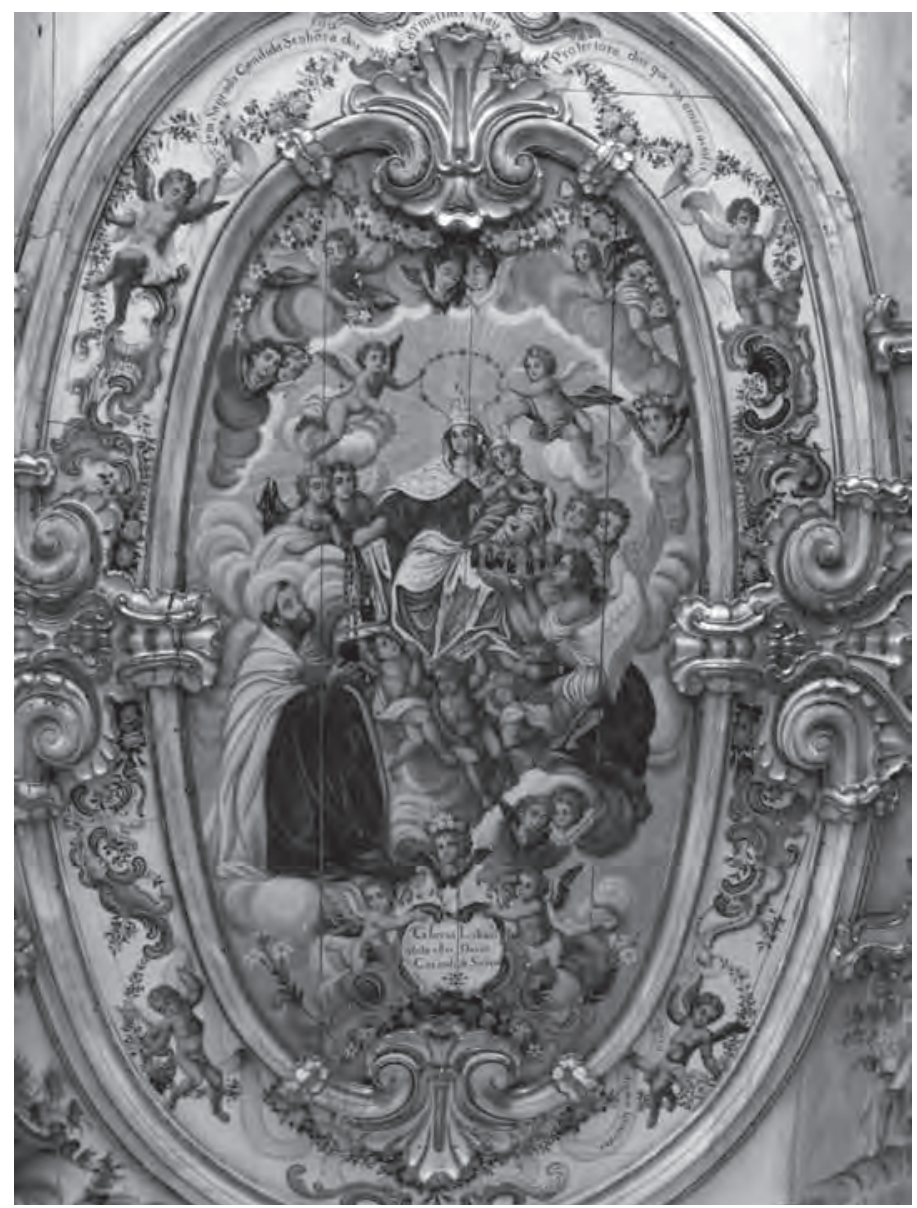

Ex.1 - Pintura de forro - Sacristia - Ordem Terceira do Carmo / Ouro Preto - MG Acervo Adalgisa Arantes Campos 
Por constituir-se como cárcere de Deus muitas vezes encontramos a iconografia dessas almas imersas nesse fogo sagrado em locais privilegiados do templo cristão, ou seja, qualificados no plano simbólico como, por exemplo, no frontal da mesa do altar, a tampa do sacrário, no camarim, coroamento dos retábulos dentre outros locais ${ }^{6}$. As almas padecentes apresentam o fogo até meio corpo e as mãos unidas em atitude de oração. Há distinção de gênero (masculino e feminino) e às vezes até de tipos sociais com seus atributos (imperador, rei, papa, frade, prostituta etc..). Há distinção da idade do padecente como na pintura existente no forro da entrada lateral direita da Catedral Basílica de São João del Rei. Algumas almas levam uma mão ao rosto, em sinal de arrependimento e horror pelos pecados cometidos. Noutras, em particular, há presença da tonsura e de gestos indicando que aquela alma situada de costas, à moda da celebração litúrgica anterior ao Concilio Vaticano II, está a "dizer missa". É comum também que elas portem o santo escapulário sobre o peito nu. Em composições heterodoxas elas tentam sair do Purgatório se apegando ao escapulário de Nossa Senhora do Carmo como se pode ver em painel de azulejo existente no Museu Machado de Castro de Coimbra.

Tais composições pressupõem o conhecimento dos favores obtidos com a devoção ao escapulário e até do Privilégio Sabatino. 0 que significa que aquela alma estaria na reta final, ou seja, deixando o Purgatório e ingressando no Paraíso. Tais almas são consideradas "santas", "benditas", "entendidas", conforme o jargão popular - em razão de sua evolução espiritual. Por estarem nessa etapa derradeira nos patamares do cárcere de Deus elas também podem realizar milagres. Há interessante exemplar de ex-votos com tal invocação no Museu da Inconfidência de Ouro Preto. É interessante destacar que os santos franciscanos, com seu escapulário respectivo, também foram venerados como intercessores das Almas do Purgatório, contudo, tal devoção não constitui nesse momento o alvo de nossa pesquisa.

\section{6 - Outras invocações carmelitas e o advento da reforma de Teresa D'Ávila}

A ordem teve em seus quadros os italianos: Santo Alberto de Sicilia (1250 -1307), André Corsini (1302 - 1373) e Maria Madalena de Pazzi (1566 - 1607), dentre outras devoções. Registra-se que o ramo feminino - a ordem segunda- cuja data de fundação é 1452, é posterior, portanto à oficialização da ordem terceira. Veneram-se também devoções alheias à ordem, tais como: Santo Antão (falecido em 256), considerado o fundador da vida eremítica; os santos de pele escura como Efigênia (Etiópia, I d.C) e Elesbão (falecido em cerca de 529) que podem ser representados com o hábito carmelita, embora essa instituição nem existisse de fato no tempo em que eles viveram. Por essa razão o devoto "despreparado" (indiferente ao tempo histórico) acredita que os dois santos foram de fato carmelitas. A ordem do Carmelo também cultuava Santa Ana, São José7 e São João Batista.

Os fundadores do Carmelo reformado ou Carmelo Descalço foram: Teresa de Ávila (1515-1582) e João da Cruz (1542-
1591) ${ }^{8}$, espanhóis autores de uma vasta obra mística que deu ao Carmelo um certo peso intelectual. Eles fundaram em 1562 o primeiro Convento dos Carmelitas Descalços. A dupla, Teresa e João, preocuparam-se com o retorno da primitiva observância, colocando como fundamento da mística as virtudes teologais (fé, esperança e caridade), a humildade, a castidade, a pobreza, a penitência e a mortificação. Ambos constituem devoções específicas da época Barroca, período de um catolicismo reformado.

Teresa deixou obras como 0 Caminho da perfeição, 0 castelo interior, As moradas e o livro biográfico Sua vida. Teve inúmeras visões místicas, contudo a tradição iconográfica veiculou sobremaneira a transverberação. Nela um serafim traspassa o peito da abadessa carmelita com uma flecha em fogo causando-lhe uma grande ferida, visivel em seu coração que permaneceu incorrupto ${ }^{9}$. Em pintura de Rubens (1577-1640) sob guarda do Museu Real de Belas Artes em Anvers e já divulgada por MÂLE (1934), Teresa intercede junto a Cristo em favor das almas do Purgatório. No plano devocional - e a iconografia tratou de deixar claro e de divulgar tais representações - a reformadora culta e mística assume o papel de mediadora entre a Jerusalém Padecente e a Jerusalém Celeste, sendo também representada em solilóquios frequentes com os seres celestiais. Ela faleceu em 1582, em 1614 foi beatificada e canonizada em 1622. Sua festa é celebrada em 15 de outubro ${ }^{10}$.

Na obra de João da Cruz sobressaem A subida ao Monte Carmelo, A noite escura da Alma, Cânticos Espirituais e a Chama de amor viva. Ele foi canonizado em 1726 pelo papa Benedito XIII e sua comemoração é feita em 14 de dezembro. Sua iconografia, no entanto, é mais culta, não apelando para prodígios. É representado com o hábito da ordem, portando em uma das mãos o crucifixo. ${ }^{11}$

\section{7 - 0 brasão dos carmelitas}

Para se reconhecer uma edificação, altar ou alfaia dos carmelitas basta a identificação de seu escudo. Nele destaca-se ao fundo a presença do Monte Carmelo em marrom, como uma recordação do manto de Nossa Senhora. As três estrelas simbolizam os fundadores (míticos) da ordem: a estrela isolada representa a Virgem do Carmo, as outras duas o profeta Elias e Eliseu (LEONARDINI \& BORDA, 1996, p.50-51). Nas laterais pode ocorrer a presença de serafins sustentando escapulários, e no arremate a coroa de Nossa Senhora.

Existe uma segunda modalidade de escudo que pressupõe a reforma de Teresa: "Um segundo escudo es empleado por los carmelitas descalzos; éste tiene en la cima de la montaña, la cruz agregada por san Juan de la Cruz en la época de la Reforma, la cual representa a Cristo" (LEONARDINI \&t BORDA, 1996, p.50-51).

Contudo, é bom ressaltar que nem sempre a presença dos ditos escudos e mesmo das devoções citadas esclarecem se de fato o que se vê é o Carmelo Observante ou o Carmelo Reformado, pois em ambos houve a tendência a fundir a sua iconografia. 


\section{8 - A inserção do território americano na crença dos carmelitas}

Tanto os Carmelitas Descalços quanto os Calçados (Observantes) vieram ao território americano português. A primeira remessa de religiosos chega em 1580, liderados pelo Frei Bernardo Pimentel. Não raro houve conflitos entre essas duas vertentes. Observa-se que nesse tempo já existia o braço reformado do Carmelo (datado de 1562). Considerando que 0 ano de 1580 marca o início da União das Coroas ibéricas que prossegue até 1640 , o período foi bastante propício para a expansão dos estabelecimentos dos dois reformadores espanhóis. Incontestavelmente houve uma absoluta rapidez na instalação de seus conventos e hospícios.

Estiveram eles localizados nas seguintes regiões: em Pernambuco: Olinda - Convento do Carmo (1583) e Convento de Santa Tereza ${ }^{12}$ (1687), Recife (1631) e Goiana (1636); em São Paulo: Santos (1589), capital paulista (1594), Mogi das Cruzes (1629) e Itú (1719) ${ }^{13}$; no Rio de Janeiro: capital carioca - Convento do Carmo (1590) e Convento de Santa Teresa (1744) e Angra dos Reis (1623); em Sergipe: São Cristóvão (1600) - que atualmente pertence ao Mosteiro de São Bento; na Paraiba: João Pessoa ${ }^{14}$ (1608) e Hospício em Lucena (1591); na Bahia: Cachoeira (século XVII), Rio Real (1683) e Hospício do Pilar em Salvador (1691); no Maranhão: São Luiz (1616); no Pará: Belém do Pará (1624) ${ }^{15}$ e no Espírito Santo: Vitória (anterior a 1685). Salienta-se que as datas referidas aludem às edificações primitivas ou ao ano em que foram lançadas as respectivas pedras fundamentais dos edificios definitivos. Os conventos pertenceram à Província Carmelitana de Portugal até que, em 1720, instituiu-se a Província Carmelitana Fluminense. Devido ao evidente crescimento da ordem na América Portuguesa, foram instituídas três Províncias: a do Rio de Janeiro, a da Bahia e a de Pernambuco (PEDRAS, 2000).

Os carmelitas possuiam construções conforme a tradição monástica herdada da Idade Média, ou seja, estabelecimentos robustos e sólidos, com fachada composta por galilé e torre sineira. 0 complexo arquitetônico envolvia o claustro, as celas (aposentos dos religiosos), dependências de serviços, a sacristia, a capela conventual e um templo contíguo - quando havia a presença da ordem terceira. Os reformadores, Teresa D'Ávila e João da Cruz, tiveram preocupação explícita com a austeridade e a modéstia das construções do Carmelo. Teresa registrou nas Constituições de 1581 as medidas que as celas, o templo conventual e o claustro deveriam ter.

Segundo ela a extensão das igrejas carmelitas deveria oscilar entre sete ou oito metros e, conforme essa medida, se guardar a devida proporção para a largura e a altura. A extensão de uma extremidade à outra do claustro não poderia ser maior que 18 metros e nem menor que 16 metros. Os aposentos dos religiosos não poderiam exceder três metros quadrados (SEBASTIÁN, 1989, p.239-249). Grosso modo, tais medidas constituem o cânon arquitetônico da ordem. Resta saber se na América Portuguesa tal norma de fato foi seguida, uma vez que houve inúmeros reaproveitamos de construções primitivas e edificações realizadas em datas distintas com donativos de devotos beneméritos ou incentivos da Coroa Portuguesa ${ }^{16}$.

Vimos que Simão Stock criou as confrarias do escapulário. Tais devotos seguiram o carisma dos Carmelitas, contudo, sem fazer o voto de castidade e de clausura. Eles recebiam orientação dos frades do convento contíguo e inspeção anual do superior da Província.

\section{9 - Os templos dos terceiros carmelitas em Minas Gerais}

Excepcionalmente no território das Minas Gerais, aonde frades chegaram a entrar individualmente, mas não puderam se estabelecer, os templos dos terceiros carmelitas se inscrevem solitariamente na paisagem dos núcleos urbanos e não mais anexos à arquitetura conventual como no litoral. Ressalta-se que, embora desligados fisicamente dos conventos, suas capelas foram erigidas em lugares importantes dos núcleos citadinos coloniais geralmente a partir de meados do século XVIII quando a sociedade se encontrava bastante estratificada. Instalaram-se legalmente em São João del Rei (1746), Mariana (antes de 1751), Vila Rica (1752), Tejuco (1758) e Vila do Príncipe (atual Serro) originada daquela do Tejuco, em 1761, Sabará (1761) (BOSCHI, 1986 / ÂNGELO, UFMG, 1999).

Na América Portuguesa, as Ordens Terceiras - envolvidas com a vida cotidiana da comunidade cristã - foram responsáveis por um mecenato artístico que envolvia mão de obra qualificada para a arquitetura, ornamentação, música, etc... A celebração de seus rituais litúrgicos implicava na aquisição de armações efêmeras, gastos com decoração de andores e compra de velas, bem como o pagamento de músicos e encomenda de sermões para ocasiões especiais. Todo o cuidado era dedicado aos atos solenes como os cortejos processionais de Nossa Senhora do Carmo (realizado em 16 de julho) e das cerimônias quaresmais, a saber: Procissão do Triunfo (Domingo de Ramos) e Procissão do Enterro (Sexta-feira da Paixão). Sem dúvida, a mais relevante era a procissão do Triunfo, pois acarretava o adorno de andores relativos aos sete passos da Paixão de Cristo tratada anteriormente em estudo específic ${ }^{17}$.

As vicissitudes dos carmelitas, e das ordens religiosas em geral, começaram no reinado de D. Maria I (1777-1816) que proibiu a aceitação de noviços. Essa ação resultou em notório envelhecimento e esvaziamento dos inúmeros conventos da época, absolutamente em decadência no século XIX. ${ }^{18}$ Sem contar com seus guardiões, o rico patrimônio colonial que o Carmelo constituiu - composto de edifícios e de seu recheio artístico - ficou deteriorado e extremamente degradado. ${ }^{19}$ Destaca-se que no caso particular dos Carmelitas Descalços, considerados defensores da Coroa Portuguesa, o prejuizo foi maior. Essa situação de abandono só foi revertida quando o Estado ou a diocese respectiva assumiu a responsabilidade sobre os monumentos religiosos. 

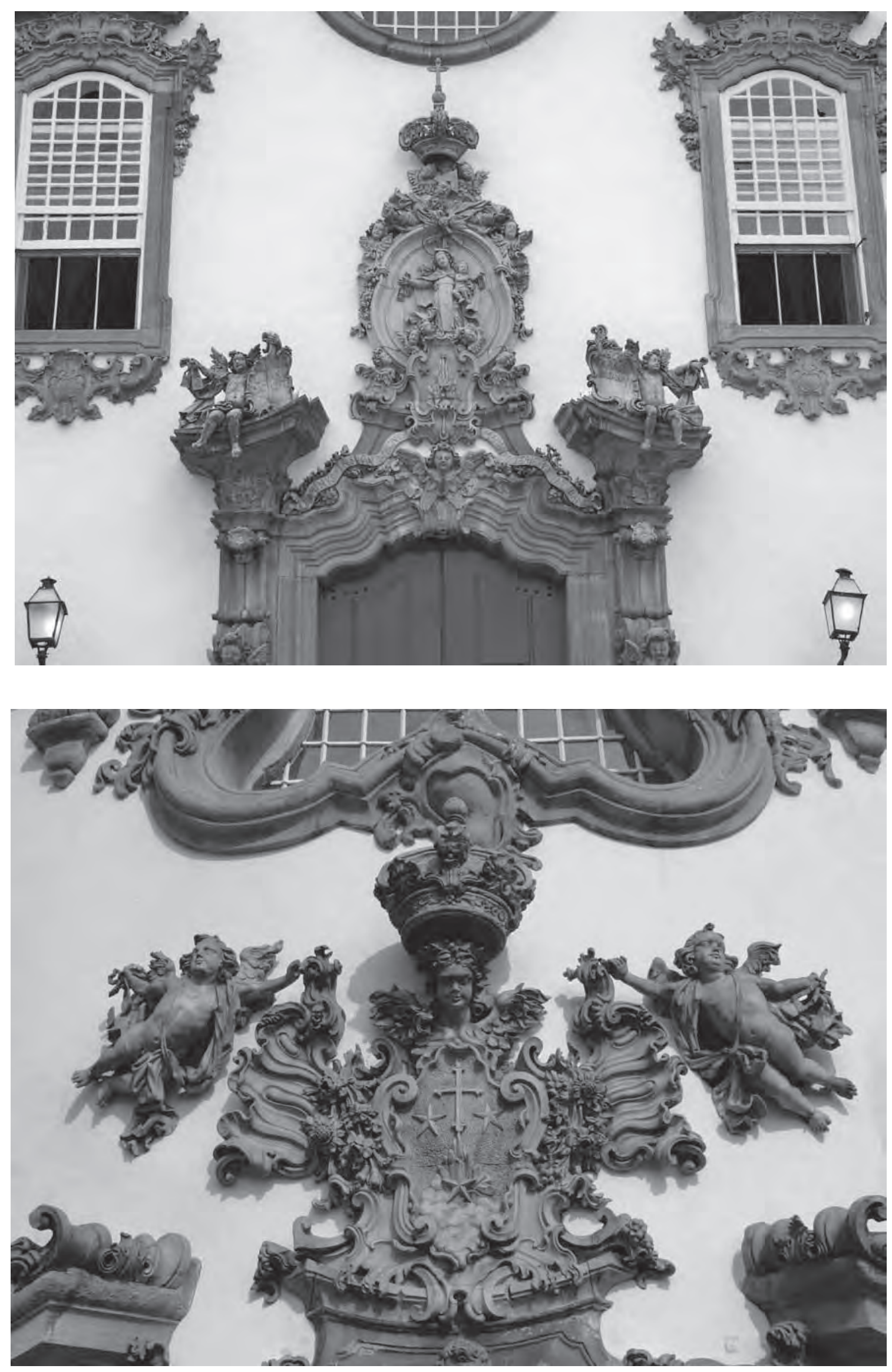

Ex.2. Portadas: A - Capela da Ordem Terceira do Carmo, São João Del Rei, MG (Acervo Adalgisa Arantes Campos); B - Capela da Ordem Terceira do Carmo Ouro Preto, MG (Foto de Antônio Cubero). 


\section{Referências}

ALGRANTI, Leila Mezan. Honradas e Devotas: mulheres da Colônia condição feminina nos conventos e recolhimentos do Sudeste do Brasil, 1750 -1822. Brasília; Edunb/José Olympio, 1993.

ÂNGELO, Rosa Figueiredo. A Venerável Ordem Terceira de Nossa Senhora do Carmo do Sabará: pompa barroca, manifestação artística e as cerimônias da Semana Santa (XVIII a meados do XIX). Dissertação de Mestrado em História, UFMG, 1999.

BOSCHI, Caio C. Os leigos e o poder: irmandades leigas e política colonizadora em Minas Gerais). São Paulo: Ática, 1986.

CAMPOS, Adalgisa Arantes. Cultura artística e calendário festivo no barroco luso-brasileiro: as Ordens Terceiras do Carmo. Imagem Brasileira. Belo Horizonte, v.2, 2003.

GONÇALVES, Flávio. 0 Privilégio Sabatino na arte alentejana. In: Separata de A cidade de Évora. Évora, n. 45 e 16 (1963). HOORNAERT, Eduardo. A evangelização do Brasil durante a primeira época colonial. In: A. A. V. V. História Geral da lgreja na América Latina. Petrópolis: Vozes. Tomo II, 1977.

LE GOFF, Jacques \&t SCHIMIT, Jean-Claude. Dicionário temático do Ocidente Medieval. Tradução de Hilário Franco Júnior. Bauru: EDUSC, 2006. V. II.

. 0 nascimento do Purgatório. 2. ed. Lisboa: Estampa, 1995.

LEONARDINI, Nanda \& BORDA, Patricia. Diccionario iconografico religioso peruano. Lima: Rubican editores, 1996.

MACKENZIE, John L. Dicionário Bíblico. São Paulo: Paulus, 1983.

MÂLE, Emile. L'art religieux aprés le Concile de Trente. Paris: Armand Colin, 1934.

OLIVEIRA, Carla Mary. 0 Barroco na Paraíba arte, religião e conquista. João Pessoa: Editora UFPb, 2003.

PEDRAS, Beatriz Junqueira. Uma Leitura do I Livro de Tombo do Convento do Carmo em Salvador: contribuição à construção histórica da ordem dos carmelitas na Bahia colonial. Dissertação de Mestrado em Ciências da Informação, UFMG, 2000.

SEBASTIÁN, Santiago. Contrarreforma y barroco: lecturas iconográficas e iconológicas. Madrid: Alianza Editorial, 1989. SOLIMEO, Plínio Maria. A grande promessa de salvação o Escapulário de Nossa Senhora do Carmo. São Paulo: Artpress, 2000 VAZ, Henrique Cláudio L. As raízes da modernidade. São Paulo: Loyola, 2002. 


\section{Notas}

1 Eu agradeço Weslley Fernandes Rodrigues e Denise Aparecida Sousa Duarte, membros do projeto Pompa Barroca: Semana Santa, culto santoral e escatologia no Barroco luso-brasileiro, com bolsa produtividade do CNPq.

2 Atualmente, aos pés desse monte de grande altitude situa-se a cidade de Haifa (Cf. o verbete Carmelo in: MACKENZIE, 1983. p.146).

3 Sobre a crença no milagre cf. VAUCHEZ, Andre. Verbete milagre In: LE GOFF \& SCHIMITT, 2006, p.197-212.

4 No século XIX apareceram as medalhas/escapulários, feitas em metal e dotadas de duas faces (Cf. SOLIMEO, 2000).

50 pensamento leigo nasce no interior do medievo (cf. VAZ, 2002).

6 Geralmente tal iconografia é registrada também para deixar claro que determinadas alfaias são de propriedade das irmandades de São Miguel e Almas. Portanto não constitui um atributo específico das Ordens terceiras do Carmo.

CAMPOS, Adalgisa Arantes IN: "A portada da Capela de São Miguel e a veneração às almas do purgatório, Vila Rica - Brasil (século XVIII)" IN: SCHUMM, Petra (ed.) Barrocos y Modernos nuevos caminos en la investigación del Barroco iberoamericano. Frankfurt: Vervuert, Madrid: Iberoamericana, 1998. p.231- 241.

7 Teresa d'Ávila teve São José como santo patrono e protetor (cf. LEONARDINI \&t BORDA. 1996, p.239).

8 A história registra que João da Cruz, teólogo e místico era o confessor de Teresa de Ávila.

9 Teresa d'Ávila teve São José como santo patrono e protetor (cf. LEONARDINI \&t BORDA. 1996, p.239).

10 Somente em 1970 foi proclamada pelo papa Paulo VI como primeira doutora da Igreja.

11 Na pintura pode vir em contexto de mortificação e penitência ou escrevendo no interior de cárcere da inquisição (cf. LEONARDINI \& BORDA. 1996, p.156).

12 Sobre conventos femininos, em número bem menor que os masculinos (cf. ALGRANTI, 1993).

13 Na região da Capitania São Paulo destacou-se o artista mulato Padre Jesuíno do Monte Carmelo (segunda metade do século XVIII), pintor e dourador nativo da cidade de Santos. Esse artista foi muito estudado por Mário de Andrade.

14 Sobre beneditinos, carmelitas e franciscanos em João Pessoa (cf. OLIVEIRA, 2003).

15 Os Carmelitas foram considerados excelentes defensores das fronteiras do Império Português no interior do vale Amazônico (HOORNAERT, 1977. p.19-152).

16 Poucos são os estudos científicos sobre o ideário e os estabelecimentos carmelitas no Brasil. Mesmo Germain Bazin, que tanto estudou o Barroco luso-brasileiro, não dedicou um capítulo específico a tal ordem religiosa.

17 Normalmente tais devoções permaneciam expostas à veneração nos altares laterais dos templos terciários, constituindo-se, portanto, em imagens retabulares e processionais. Salienta-se, todavia, que nem todas as ordens terceiras possuiam a totalidade dos passos representativos da Paixão de Cristo (da Oração do Horto até o Sepultamento). Sobre a Procissão do Triunfo, especificamente realizada pelos Carmelitas, (Cf. CAMPOS, 2003, p.15-25).

18 A partir de 1759, a administração portuguesa implementou restrições políticas e econômicas às ordens religiosas. É bastante numeroso o conjunto de leis outorgadas em prejuizo de todas essas ordens.

190 pensamento ilustrado em ascensão no último quartel do XVIII e que atinge o XIX, levou a desamortização de muitos bens anteriormente dos religiosos, considerados "bens de mão morta". Aos bispos é facultado alienar as propriedades eclesiásticas. Cf. PERUJO, verbete "Bienes de beneficiencias, obras-pias" e "Bienes de la Iglesia". t.2, p.261-263 e 263- 266. Portanto, não se trata de um capricho da rainha dona Maria I ou de seu ministro, conde de Oeiras, o Marques de pombal.

Adalgisa Arantes Campos é professora do Departamento de História - desde 1986 - e do respectivo Programa de Pósgraduação da Universidade Federal de Minas Gerais - UFMG; pesquisadora do Conselho Nacional de Desenvolvimento Científico e Tecnológico - CNPq; membro do Comitê Brasileiro de História da Arte - CBHA. É Licenciada e Bacharel em História pela Faculdade de Filosofia e Ciências Humanas da Universidade Federal de Minas Gerais/UFMG, Especialista em Cultura e Arte Barroca pelo Instituto de Filosofia, Artes e Cultura da Universidade Federal de Ouro Preto - UFOP, Mestre em Filosofia pela UFMG, Doutora em História Social pela Universidade de São Paulo -USP. Em suas pesquisas contempla a pompa dos ritos religiosos litúrgicos e extra-litúrgicos, a cultura artística na Época Moderna, o mecenato das irmandades leigas e ordens terceiras, os rituais quaresmais e da Semana Santa na América Portuguesa e o ideário da morte. Realizou estudos pós-doutorais sob a supervisão da Profa. Dra. Myriam Andrade Ribeiro de Oliveira (UFRJ). 